\title{
Mercosul e a harmonização das legislações que informam a determinação das alíquotas do imposto sobre a importação ${ }^{1}$
}

Eloísa Cristina Werdenberg ${ }^{2}$

Fábio Vinícius Gorni Borsato ${ }^{3}$

\section{Resumo}

O presente trabalho tem por objetivo demonstrar que para uma integral harmonização entre os países membros do Mercosul faz-se necessário a solução dos conflitos existentes entre as normas de cada país. O maior choque verificado no âmbito do imposto sobre a importação resido no aparente conflito entre a ausência do princípio da anterioridade para alterar as alíquotas do referido imposto com o princípio da não discriminação entre os signatários do Mercosul.

Palavras-Chave: Mercosul; Princípio da anterioridade, Princípio da não-discriminação.

\section{Introdução}

Com o fim da Guerra Fria iniciou-se uma corrida entre os países para a formação de blocos econômicos, com o objetivo de fortalecer a econômica através da quebra de barreiras alfandegárias.

Como não poderia ser diferente, a América Latina também começou a firmar Tratados Internacionais para formação de blocos econômicos, sendo o de maior expressão o Mercosul, do qual o Brasil é signatário.

Atualmente, o Mercosul encontra-se no estágio de uma União Aduaneira imperfeita, pois, há um Código Aduaneiro comum a todos os signatários, porém as normas nele contidas não foram recepcionadas integralmente pelos países membros, isso significa que para vários assuntos os Estados-membros aplicam suas próprias normas de direito tributário interno, motivo que dificulta as relações entres os países e a harmonização das legislações.

Dentre esses problemas verificados no âmbito do Mercosul pode-se destacar a questão da não incidência do princípio da anterioridade no que tange a alteração das

\footnotetext{
Trabalho apresentado como requisito parcial de conclusão da disciplina de Direito Tributário do curso de Direito da Universidade Estadual de Londrina.

2 Graduanda em Direito pela Universidade Estadual de Londrina. eloisa@sercomtel.com.br.

3 Graduando em Direito pela Universidade Estadual de Londrina. fabioborsato@ibest.com.br.
} 
alíquotas do imposto sobre a importação vigente no ordenamento brasileiro, o qual conflita com o princípio da não discriminação constante no artigo 7ํ do Tratado de Assunção.

\section{Mercosul e sua formação}

Com o final da Segunda Guerra Mundial, o mundo sofreu importantes transformações nas áreas política e econômica, forçando uma integração entres os países, através da formação de grupos regionais, como é o caso do Mercosul.

O Mercado Comum do Sul é um projeto que começou a ser idealizado por Brasil e Argentina, numa iniciativa da Argentina de criar um bloco austral, diante das necessidades econômicas vivenciadas por ambos, por volta de 1941. No entanto, por divergências entre os dois países em decorrência da Segunda Guerra Mundial, as negociações paralisaram-se. Contudo, em meados dos anos 80 , as negociações foram retomadas e o Mercosul teve sua primeira institucionalização em 1991 por meio do Tratado de Assunção.

O objetivo principal do Mercosul é harmonizar as legislações dos Estados-membros, nas áreas pertinentes, para fortalecer o processo de integração regional, construir um mercado consistente com o menor grau de distorções, bem como reduzir a carga tributária decorrente das operações realizadas entres os países signatários. É esse entendimento disposto no artigo 1ㅇ do Tratado de Assunção:

\footnotetext{
Art. 10 - A livre circulação de bens, serviços e fatores produtivos entre os países, através, entre outros, da eliminação dos direitos alfandegários e restrições nãotarifárias à circulação de mercadorias e de qualquer medida de efeito equivalente; O estabelecimento de uma tarifa externa comum e a adoção de uma política comercial comum em relação a terceiros Estados ou agrupamentos de Estados e a coordenação de posições em foros econômicos-comerciais regionais e internacionais;

A coordenação de políticas macroeconômicas e setoriais entre os Estados Partes de comércio exterior, agrícola, industrial, fiscal, monetária, cambial e de capitais, de serviços, alfandegária, de transportes e comunicações e outras que se acordem, a fim de assegurar condições adequadas de concorrência entre os Estados Partes de harmonizar suas legislações, nas áreas pertinentes, para lograr o fortalecimento do processo de integração.
}

Verifica-se que a coordenação seria o estabelecimento de metas comuns e a adoção de medidas isoladas pelos Estados-Membros, os quais devem se comprometer a respeitarem as decisões tomadas em comum acordo. Já a harmonização preocupa-se mais 
com os princípios legislativos, ou seja, os países agora devem fixar princípios inerentes e compatíveis com a legislação de cada Estado-Membro, visto que, os mesmos deverão ser obedecidos pelas legislações de cada país.

Essa harmonização foi parcialmente obtida em 1995, com o Protocolo de Ouro Preto, através do qual o Mercosul assumiu o formato de uma união aduaneira, ou seja, nesse estágio os países membros derrubam as barreiras alfandegárias e passam a praticar uma taxação igual em relação à importação e exportação de produtos, mercadorias e serviços oriundos de outros países não pertencentes à união aduaneira.

Quando o Mercosul passou a ser uma união aduaneira foi criada a Tarifa Externa Comum (TEC) para os países membros, a qual encontra-se atualmente regulamentada pela Resolução $n^{\circ}$ 42/2001 da Siscomex, Sistema Integrado de Comércio Exterior, que é o órgão federal que controla todas as operações de comércio exterior (importações e exportações) realizadas pelo país. Já para as relações econômicas realizadas com países não pertencentes ao Mercosul ficou estabelecida a aplicação da Taxa Externa Básica, que geralmente é superior a TEC.

No entanto, esse processo de harmonização tributária é bastante complexo, pois não implica necessariamente na uniformização do conjunto das normas tributárias, inclusive as relativas aos incentivos fiscais, mas possui como meta principal eliminar as distorções que afetam as relações econômicas, e tornar os sistemas tributários dos países membros compatíveis com a adoção de critérios comuns.(RIBEIRO, 2002, p. 02)

Os maiores problemas enfrentados pelo Mercosul para que haja uma harmonização das legislações são as diferenças de estruturas, regulamentação e aplicabilidade dos tributos, bem como bases de incidências e alíquotas diferenciadas dos impostos entre os diferentes Estados, que podem causar uma justaposição de sistemas, conseqüentemente uma dupla cobrança dos mesmos tributos, e, somente quando se consegue erradicar esses problemas e aproximar os sistemas fiscais é que se depara com as medidas de harmonização.(FERNANDES, 1999, p. 195)

O Mercosul encontra-se atualmente no estágio da união aduaneira incompleta, visto que, a constituição desta união aduaneira pressupõe a existência de um território que possua as mesmas regras de comércio exterior, ou seja, conforme explica Edison Fernandes, "é necessário que as normas tributárias com relação a essas transações, ou seja, o 
regulamento aduaneiro deve ser unificado, havendo somente um conjunto de normas aduaneiras obedecidas por todos os Estados-Membros".(FERNANDES, 1999, p. 214).

Todavia, através da Resolução 13/94 foi encomendada ao Subgrupo de trabalho no 02 a elaboração de um projeto de Código Aduaneiro do Mercosul. Esse projeto foi concluído na VII Reunião do CMC, em Ouro Preto, sendo aprovado pela Dec. 25/94 como Protocolo Relativo ao Código Aduaneiro do Mercosul, o qual, procurou disciplinar "aspectos fundamentais do comércio exterior do bloco econômico, tais como elementos de base para a aplicação dos gravames aduaneiros - dentre eles a Tarifa Externa Comum, o Regime de Origens e a Valoração Aduaneira -, destinação aduaneira das mercadorias, infrações aduaneiras etc." (FERNANDES, 1999, p. 215). Porém esse protocolo não foi ratificado na sua integra por nenhum dos quatros Estados-Membros, motivo pelo qual ainda há a ocorrência de conflitos tributários entre as legislações dos países signatários do Mercosul.

\section{Integralização e constitucionalidade dos tratados internacionais do Mercosul em matéria tributária}

No que tange aos tratados internacionais e especificamente quanto ao bloco regional do Mercosul, muito se discute sobre a forma de integralização daqueles tratados e, em contrapartida, a observância aos princípios constitucionais tributários presentes no ordenamento jurídico interno.

Alcançou-se o entendimento de que em matéria tributária, não existe cláusula pétrea, o que indica que leis inferiores, na qual se incluem os tratados integralizados, podem alterar alíquotas, hipóteses de incidência, desde que não confrontem com a Carta Magna.

A esse respeito, as lições de Ives Gandra da Silva Martins:

ocorre que, em matéria tributária, salvo os expressos princípios fundamentais exteriorizados no artigo 150 e, também, espalhados por outros dispositivos de forma expressa, não há cláusula pétrea, podendo emendas constitucionais e legislação inferior alterar regimes jurídicos, alíquotas, incidências, tributos, inclusive criando-os, sem que haja ferimento à lei suprema. (MARTINS, 2002, p. 23).

Os tratados internacionais, portanto, que versem sobre matéria tributária, entre eles os do Mercosul e, especificamente, o Tratado de Assunção em nada atacam a questão 
da constitucionalidade do regime jurídico tributário que encontra respaldo na norma constitucional, de forma que a sua inclusão no sistema é amplamente recebida, mas desde que não implique na afronta direta a dispositivo da constituição, ou mesmo outro tratado internacional, como é o caso da Declaração Universal dos Direitos do Homem que foi recepcionada na categoria dos direitos e garantias fundamentais, sendo ela cláusula pétrea.

Não há que se falar, outrossim, em conflito de normas e princípios constitucionais, tendo de um lado a norma programática do artigo 4ํㅡ, parágrafo único, da Constituição Federal, que aborda a integração econômica dos países em blocos regionais, face às normas constitucionais de soberania nacional (artigo 1으 e 4으, inciso I, da CF/88) e a conseqüente possibilidade do próprio estado disciplinar, sem a interferência de interesses externos, a política tributária nacional, bem como as normas fechadas do sistema tributário, no que tange ao princípio da estrita legalidade e da tipicidade fechada.

\section{Princípio da anterioridade no imposto sobre a importação e sua relação com a harmonização do Mercosul}

Pelo exposto até o momento, percebe-se que a maior dificuldade para a perfeita integração regional entre os países do Mercosul encontra-se na problemática de harmonizar as legislações dos Estados-Membros.

O problema torna-se ainda mais complexo quando verificamos que entre os países pertencentes ao Mercosul, somente o Brasil possui um sistema constitucional tributário organizado e exaustivo, conforme se verifica no Título VI da Constituição Federal que enumera as normas atinentes à tributação, dispondo sobre o sistema tributário nacional, abordando sobre a competência tributária dos entes federados, bem como os princípios aplicados à tributação.

Entre os princípios aplicados no campo da tributação, o princípio da anterioridade é o que maior complicações pode causar para o processo de harmonização do Mercosul, pois o referido princípio encontra-se estabelecido no artigo 150, III, b, da CF, o qual explica Roque Antônio Carrazza "veda a aplicação da lei instituidora ou majoradora do tributo sobre fatos ocorridos no mesmo exercício financeiro em que entrou em vigor" (CARRAZZA, 2005, p. 185). 
Trata-se de uma forma de garantir uma previsibilidade e segurança ao contribuinte sobre quais impostos deverá arcar no exercício financeiro seguinte conforme explica Francisco Pinto Rabello Filho ao citar as lições de Geraldo Ataliba, que o princípio da anterioridade possui como objetivo proporcionar estabilidade e segurança ao contribuinte,

\begin{abstract}
no sentindo de que é preciso haver clima de segurança e previsibilidade acerca das decisões do governo para que a liberdade de iniciativa e o direito de trabalhar, produzir, empreender e atuar numa economia de mercado não sejam meras figuras de retórica, sem nenhuma ressonância prática. De fato, o empresário precisa fazer planos, estimar - com razoável margem de probabilidade de acerto os desdobramentos próximos da conjuntura que vai cercar seu empreendimento. Precisa avaliar antecipadamente seus custos, bem como estimar os obstáculos e as dificuldades. Já conta com os imponderáveis do mercado. Não pode sustentar um governo que agrave - com suas surpresas e improvisações - as incertezas, normais preocupações e ônus da atividade empresarial. (RABELLO FILHO, 2002, p. 101).
\end{abstract}

No entanto, dispõe o artigo 150, § 1ำ da CF que o princípio da anterioridade não se aplica no imposto sobre a importação, sendo permitido ao Poder Executivo modificar as normas atinentes à importação sem o devido respeito ao princípio da anterioridade, ou seja, a lei que majorar ou diminuir as alíquotas aplicadas aos impostos sobre a importação poderão ser aplicadas imediatamente após a sua entrada em vigência, ferindo a segurança jurídica proporcionada aos contribuintes no que se referem aos demais tributos.

Essa exceção ao princípio da anterioridade aplicada ao imposto sobre a importação explica Carrazza que "dizem respeito a tributos federais e têm o louvável propósito de propiciar à Nação os indispensáveis meios de defesa contra situações extremas (guerra externa ou sua iminência, guerra de tarifas internacional, incontrolável evasão de divisas, necessidade de proteger a industria nacional contra importações despropositadas etc.)". (CARRAZZA, 2005, p. 199).

Percebe-se que essa violação ao princípio da anterioridade, o qual proporciona uma segurança jurídica ao contribuinte, deve ser analisada com cuidado, pois, se verificar a questão sob o aspecto da proteção do mercado interno quando verificada a prática de alíquotas que o prejudicam, faz-se necessário realmente à exclusão do princípio da anterioridade.

Essa proteção torna-se efetiva com a aplicação do caráter da extrafiscalidade dos impostos, o qual é marcado pelo caráter regulatório imposto pelo Estado, sendo que a cada 
dia as atribuições que Ihe são conferidas se multiplicam, o que justifica a intervenção direta na sociedade, distanciando-se, por este aspecto, da faceta exclusivamente arrecadatória dos tributos.

Para Paulo de Barros Carvalho, consiste a extrafiscalidade:

no emprego de fórmulas jurídico-tributárias para obtenção de metas queprevalecem sobre os fins simplesmente arrecadatórios de recursos monetários, o regime que há de dirigir tal atividade não poderia deixar de ser aquele próprio das exações tributárias. Significa, portanto, que, ao construir suas pretensões extrafiscais, deverá o legislador pautar-se, inteiramente, dentro dos parâmetros constitucionais, observando as limitações de sua competência impositiva e os princípios superiores que regem a matéria, assim os expressos que os implícitos. (BARROS CARVALHO, 2005, p. 236).

No imposto de importação a suscetibilidade do estado em relação às possíveis alterações externas, essencialmente aquelas que dizem respeito às alíquotas, justifica a não incidência do princípio da anterioridade.

Por outro lado, quando se olha para a questão da integração regional intentada pelo Mercosul, a não incidência do princípio da anterioridade sobre as normas que regulamentam sobre as alíquotas do imposto sobre a importação poderá prejudicar as relações entre os países membros, ao passo que serão surpreendidos com alíquotas novas que não estavam previstas anteriormente.

\section{0 conflito entre o princípio da anterioridade e o princípio da não-discriminação}

Entre os princípios que se aplicam à tributação, o princípio da anterioridade previsto no artigo 150, III, b, da CF é um dos que mais causam problemas para a integração dos países do Mercosul conforme analisado anteriormente, visto que se choca com o princípio da não-discriminação previsto no artigo 70 do Tratado de Assunção, o qual estabelece que "em matéria de impostos, taxas e outros gravames internos, os produtos originários do território de um Estado Parte gozarão, nos outros Estados Partes, do mesmo tratamento que se aplique ao produto nacional".

Percebe-se que esse artigo possui como objetivo dar um tratamento isonômico entre os produtos dos Estados-Membros, "não podendo haver qualquer discriminação ou barreiras tributárias ao comércio intra-reginal" (FERNANDES, 1999, p. 64-71). 
Em virtude desse tratamento isonômico que o Mercosul criou duas categorias de produtos, isto é, os produtos trazidos de países-membros e aqueles trazidos de países, ou blocos de países, externos ao Mercosul. Para os países pertencentes ao Mercosul aplicar-seá a Tarifa Externa Comum (TEC), já para os países que não pertencem ao bloco econômico será incidido a Taxa Básica Externa. Isso ocorre por causa do objetivo principal do Mercosul, ou seja, a eliminação de barreiras tarifárias entre seus membros.

Ao criar a TEC o Mercosul não buscou única e exclusivamente a eliminação total das formas de proteção ao mercado nacional, visto que o próprio artigo 2 o do anexo IV, do Tratado de Assunção prevê a possibilidade da alteração das alíquotas referentes ao imposto sobre a importação toda vez que a importação de determinado produto cause ou ameace causar prejuízo grave ao setor nacional relacionado com os bens similares ou diretamente concorrentes aos importados. Dispõe o artigo 2으 do referido tratado o seguinte: "se as importações de determinado produto causarem dano ou ameaça de dano grave a seu mercado, como conseqüência de um sensível aumento, em um curto período, das importações desse produto provenientes dos outros Estados Partes, o país importador solicitará ao Grupo Mercado Comum a realização de consultas com vistas a eliminar essa situação".

Percebe-se que o Tratado de Assunção previu a possibilidade de alteração das alíquotas referentes às importações, no entanto, exige-se que seja comunicada e comprovada a real necessidade da modificação, não podendo esta ocorrer de forma discricionário por parte dos países membros do Mercosul.

É justamente nesse ponto que reside o conflito entre a não exigência do princípio da anterioridade sobre os impostos sobre a importação e o princípio da não-discriminação entre os países signatários do Mercado Comum do Sul.

Como ficaria a situação do estado - membro que, com fundamento na extrafiscalidade e a desnecessidade de observar o princípio da anterioridade tributária, como o Brasil, alterasse a alíquota do imposto de importação sobre determinado produto sem a comunicação aos demais integrantes do bloco, sob a alegação de prejuízo ao mercado interno? 
Em relação a esta questão, conclui-se que o confronto entre o princípio da anterioridade e a sua não exigência com o princípio da não discriminação no Mercosul estará resolvido com a própria aplicação das alíquotas previstas na Tarifa Externa Comum (TEC).

A elaboração da TEC e a sua nomenclatura comum a todos os estados integrantes do bloco regional é realizada com a participação de todos, como é comum aos tratados internacionais, de modo que a sua formação e as alíquotas que ali constam estão carregadas de um conteúdo que é resultado da manifestação de vontade e dos interesses nacionais dos estados relativos àquele critério quantitativo do imposto de importação e a própria necessidade de proteção à atividade interna conjugada com os interesses em expansão do Mercado Comum do Sul.

Quando verificado, portanto, o advento de uma situação externa que demonstre a necessidade de modificação da alíquota do imposto de importação constante da TEC, o estado-membro, deverá suscitar essa alteração dentro do bloco, visando o princípio da não discriminação e o desenvolvimento regional, sendo que, posteriormente, de forma unilateral e sob o fundamento da extrafiscalidade e da não observância do princípio da anterioridade, poderá alterar a alíquota, mas sempre dentro da própria limitação imposta pela TEC, exceto nos casos de salvaguarda nacional, previstos tanto no âmbito do Mercosul como do GATT/OMC.

No ordenamento jurídico pátrio, a inobservância dessa questão e a modificação de alíquotas para limites que superam aqueles estabelecidos no acordo internacional gera a inconstitucionalidade da medida.

Vejamos. A alteração da alíquota no imposto de importação é promovida por ato do Poder Executivo e este deverá obedecer aos parâmetros fixados em lei, conforme exposto no artigo 153, § 1ํ, da Constituição Federal.

Nesse sentido, expõe Miguel Hilú Neto:

Assumindo os compromissos internacionais acima descritos e cumpridas as formalidades previstas para a sua integração ao sistema de direito positivo interno, o Brasil teve limitado o seu poder de tributar as operação de importação às alíquotas máximas neles prescritas. Eventual extrapolação desses limites, em especial mediante ato do Poder Executivo, é inconstitucional, por ferir o previsto no artigo 153, § 1으, da CF/88. (HILÚ NETO, 2003. p. 256). 
Assim, os limites a que remete o dispositivo constitucional não estão estabelecidos em lei, razão pela qual devem ser observados os tratados e acordos internacionais firmados pelo Brasil, tanto em relação ao Mercosul quanto a outros blocos econômicos.

\section{Conclusão}

Percebe-se que o grande desafio enfrentado pelos países integrantes do Mercosul encontra-se na harmonização entre suas legislações, visto que, cada país possui normas próprias as situações referentes às relações firmadas com outros países.

O grande problema encontrado pelo Brasil no âmbito do Mercosul com relação ao imposto sobre a importação reside no âmbito da exclusão do princípio da anterioridade para as alterações das alíquotas sobre esse imposto. Isso ocorre em virtude do imposto sobre a importação possuir como objetivo a proteção do mercado interno, daí o choque desse princípio com a norma que prevê a não-discriminação entre os Estados-membros do Mercosul.

A solução para esse conflito entre as legislações é a aplicação da própria tarifa criada pelos signatários do Mercosul, na qual, estão previstas as alíquotas que devem ser aplicadas para cada situação, e uma vez ocorrendo desvirtuamento ou prejuízo para uns dos países membros, este deverá comunicar o prejuízo para o Conselho para solucionar as diferenças que estão ocorrendo.

Caso isso não seja cumprindo e cada país resolva alterar discricionariamente as alíquotas, o objetivo principal do Mercosul, que é a quebra das barreiras alfandegárias não estará sendo atingido. Assim, o grande desafio para os países do Mercosul é essa real harmonização entre as legislações.

\section{Referências}

CARRAZZA, Roque Antonio. Curso de Direito Constitucional Tributário. 21. ed. São Paulo: Malheiros, 2005.

CARVALHO, Paulo de Barros. Curso de Direito Tributário. 17. ed. São Paulo: Saraiva, 2005. FERNANDES, Edison Carlos. Sistema Tributário do Mercosul. 2. ed. São Paulo: Revista dos Tribunais, 1999. 
HILÚ NETO, Miguel. Imposto sobre Importações e Imposto sobre Exportações. São Paulo: Quartier Latin, 2003.

MARTINS, Ives Gandra da Silva (Coord.). Tributação no Mercosul. 2. ed. atual. São Paulo: Editora Revista dos Tribunais, 2002.

RABELLO FILHO, Francisco Pinto. O Princípio da Anterioridade da Lei Tributária. São Paulo: Revista dos Tribunais, 2002.

RIBEIRO, Maria de Fátima. Considerações sobre a supremacia dos tratados internacionais sobre a legislação tributária brasileira: o caso do Mercosul. Disponível em:

<www.tributarista.org.br>. Acesso em: 31 out. 2002. 
Revista de Direito Público, LONDRINA, V. 2, N. 3, P. 137-148, SET./DEz. 2007. 